\title{
Low-Density Lipoprotein Cholesterol Goal Attainment Rates by Initial Statin Monotherapy Among Patients With Dyslipidemia and High Cardiovascular Risk in Japan
}

\author{
- A Retrospective Database Analysis -
}

\author{
Tatsuya Umeda, PhD; Ai Hayashi, PhD; Akiko Harada, BSc; Kotoba Okuyama; \\ Carl A. Baxter, PhD; Shigeru Tokita, PhD; Tamio Teramoto, MD, PhD
}

\begin{abstract}
Background: To understand the recent management status in Japan, we determined the low-density lipoprotein cholesterol (LDL-C) goal attainment (GA) rate of patients initiating statin monotherapy for dyslipidemia.

Methods and Results: Dyslipidemic patients undergoing either primary prevention with high cardiovascular risk or secondary prevention (defined by 2012 Japan Atherosclerosis Society Guidelines) were retrospectively analyzed from a hospital-based claims database. In both groups, the LDL-C levels and GA rates of patients treated with intensive or standard statin monotherapy for $\geq 4$ weeks (January 2012-August 2016) were evaluated. Among 1,501,013 dyslipidemic patients, 11,695 and 9,642 were included in the primary and secondary prevention groups, respectively. A total of $94 \%$ of patients underwent statin monotherapy as the initial lipid-lowering therapy, of which most $(\geq 80 \%)$ took intensive statins. The proportions of patients in the primary prevention group who achieved an LDL-C goal $<120 \mathrm{mg} / \mathrm{dL}$ by intensive and standard statins were $81.1 \%$ and $61.2 \%$, respectively, and the proportions of those who achieved a goal $<100 \mathrm{mg} / \mathrm{dL}$ in the secondary prevention group were $73.3 \%$ and $48.1 \%$, respectively. The GA rates were similar regardless of disease complications.
\end{abstract}

Conclusions: Most patients (>70\%) in both groups achieved LDL-C management goals using intensive statin monotherapy. Further treatment approaches are required for high-risk patients not achieving LDL-C goals by initial statin monotherapy. Continuous efforts are crucial for adherence and persistence of lipid-lowering therapies.

Key Words: Cardiovascular risk; Dyslipidemia; Low-density lipoprotein cholesterol; Statins

$\mathrm{C}$ ardiovascular disease (CVD) is the leading cause of death worldwide, ${ }^{1}$ and the second leading cause of death after malignant neoplasms in Japan. ${ }^{2}$ CVD, including coronary artery disease (CAD), peripheral arterial disease (PAD), and cerebrovascular disease, is mainly caused by arteriosclerosis, and its major risk factor is an elevated level of low-density lipoprotein cholesterol (LDLC). ${ }^{3}$ Therefore, adequate control of LDL-C is crucial for preventing CVD in patients with dyslipidemia.

Lowering of LDL-C by statin therapy generally correlates with a reduced risk of $\mathrm{CV}$ events regardless of a relevant history. ${ }^{4-7}$ A meta-analysis of 26 trials showed that a reduction in LDL-C was associated with a decrease in the risk of major coronary events. ${ }^{8}$ Likewise, in Japan, a reduction in LDL-C by statin therapy significantly reduces the incidence of CAD in patients with hypercholesterolemia. ${ }^{9}$ Additionally, a greater reduction in CV events has been observed in patients undergoing an intensive rather than standard statin regimen. ${ }^{10,11}$ Based on the evidence, major international guidelines recommend statins as the first-line therapy for dyslipidemia and optimizing the intensity and dose of statins for patients at high risk. ${ }^{12,13}$

The Japan Atherosclerosis Society (JAS) guidelines for the diagnosis and prevention of atherosclerotic CVD published in 2012 recommend statins as the first-line drug treatment for management of LDL-C, together with lifestyle modification. ${ }^{14}$ The LDL-C management target in these guidelines is $<100 \mathrm{mg} / \mathrm{dL}$ for patients with a history of CAD (secondary prevention of atherosclerotic CVD) and $<120 \mathrm{mg} / \mathrm{dL}$ for patients at high risk of CAD (primary prevention with high CV risk). Practically, the LDL-C levels in patients at high risk for CVD may not be adequately managed in the real-world setting in Japan. In 2003, less than two-thirds of patients with hyperlipidemia achieved

Received September 29, 2017; revised manuscript received February 8, 2018; accepted February 15, 2018; released online April 7, 2018 Time for primary review: 11 days

Department of Medical Affairs, MSD K.K., Tokyo (T.U., A. Hayashi, A. Harada, K.O., S.T.), Japan; Center for Observational and Real-world Evidence, MSD Ltd, Hertfordshire (C.A.B.), UK; and Teikyo Academic Research Center, Teikyo University, Tokyo (T.T.), Japan

Mailing address: Tatsuya Umeda, PhD, Medical Advisor, Primary Care, Medical Affairs, MSD K.K., Kitanomaru Square, 1-13-12 Kudan-kita, Chiyoda-ku, Tokyo 102-8667, Japan. E-mail: tatsuya.umeda@merck.com

ISSN-1346-9843 All rights are reserved to the Japanese Circulation Society. For permissions, please e-mail: cj@j-circ.or.jp 


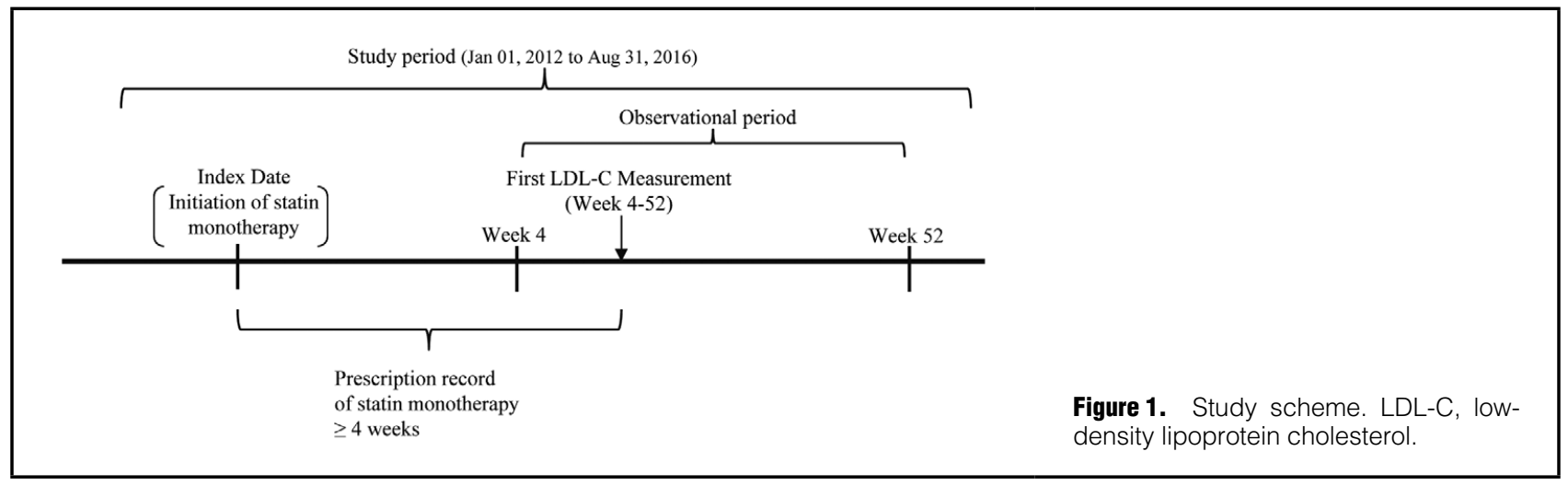

target LDL-C levels even under lipid-lowering therapy (LLT). ${ }^{15}$ In 2010, 56.5\% of patients undergoing primary prevention with high $\mathrm{CV}$ risk and $24.5 \%$ of those undergoing secondary prevention reached the LDL-C goals by statin therapy among 1,720 patients at high risk for atherosclerotic CVD in the Japan Lipid Guideline Achievement Program (JL-GAP). ${ }^{16}$ In addition to the preceding studies, it is essential to assess current LDL-C management using an updated large database in a real-world population, considering the remarkable increases in the number of dyslipidemic patients in the past few decades in Japan, as revealed by a national demographic study. ${ }^{17}$

The objectives of this study were to estimate the LDL-C goal attainment (GA) rate set by the 2012 JAS guidelines and the distribution of the LDL-C levels by initial statin monotherapy in patients with dyslipidemia at high $\mathrm{CV}$ risk, using a large database. These findings regarding current LDL-C management will raise awareness among clinicians of the importance of further appropriate management of LDL-C.

\section{Methods}

\section{Study Design and Data Source}

This retrospective observational cohort study in Japan was performed using a hospital-based claims database constructed by Medical Data Vision Co., Ltd. (MDV, Tokyo, Japan). The database consisted of healthcare claims data and laboratory test data obtained from acute care hospitals using the diagnosis procedure combination/per-diem payment system (DPC/PDPS). As of August 2016, the database comprised approximately 15.6 million inpatients and outpatients in 270 acute care hospitals, covering $16 \%$ of Japanese hospitals that use the DPC/PDPS. The diagnoses and procedure records of this administrative database have been validated in terms of their accuracy as a substitute for clinical data. ${ }^{18}$

\section{Study Population}

Patient data from 1 January 2012 to 31 August 2016 (study period) were extracted from the database. Eligible patients were $\geq 20$ years of age with a diagnostic history of dyslipidemia (identified by the 10th Revision of the International Classification of Diseases [ICD-10] codes). During the study period, the patients were required to have a prescription record of first statin monotherapy for a total of $\geq 4$ weeks, ${ }^{19-21}$ as well as at least 1 LDL-C measurement after $\geq 4$ weeks of the first statin monotherapy. No regimen change (either active ingredients or dosage) was allowed from the date of initiating statin therapy (index date) through to the earliest LDL-C measurement. Statins were classified into 2 types based on the general perception accepted among Japanese clinical practice: intensive statins (atorvastatin, rosuvastatin, and pitavastatin) and standard statins (fluvastatin, pravastatin, and simvastatin). ${ }^{22}$ Within the regulatory-approved dose regimen, the LDL-C-lowering efficacies were roughly distinguished as high or low for intensive or standard statins. ${ }^{23}$ Concomitant medications other than LLT were allowed during the study period. The detailed study scheme and patient disposition are shown in Figure 1 and Figure 2, respectively.

Patients with $\geq 1$ of the following disease complications prior to or at the index date were categorized into the primary prevention with high $\mathrm{CV}$ risk group: diabetes mellitus (DM), chronic kidney disease (CKD), noncardiogenic cerebral infarction, and PAD. Patients with a history of CAD, such as angina pectoris and/or myocardial infarction (MI), prior to or at the index date were categorized as the secondary prevention group. These prevention groups were defined based on the JAS guidelines. ${ }^{14}$ All diagnoses and conditions were identified using the ICD-10 codes. Patients who met the criteria for both prevention groups were categorized into the secondary prevention group.

\section{LDL-C Levels}

LDL-C levels of patients were determined at the earliest measurement from $>4$ to $\leq 52$ weeks after the index date while being prescribed statin monotherapy. To estimate the GA rate, the LDL-C levels were defined for each prevention group in accordance with the JAS guidelines in 2012: $<120 \mathrm{mg} / \mathrm{dL}$ for the primary prevention with high CV risk group and $<100 \mathrm{mg} / \mathrm{dL}$ for the secondary prevention group. ${ }^{14}$ Additionally, the following more aggressive LDL-C thresholds were used to evaluate the GA rates for comparison with previous studies performed outside of Japan: $<100$ and $<70 \mathrm{mg} / \mathrm{dL}$ for the primary prevention with high $\mathrm{CV}$ risk group and secondary prevention group, respectively.

The GA rates were further evaluated based on the patients' disease complications. Complications of interest included angina pectoris, MI, DM, CKD, PAD, and noncardiogenic cerebral infarction.

\section{Statistical Analysis}

All statistical analyses were stratified by the prevention group (primary prevention with high $\mathrm{CV}$ risk group and 


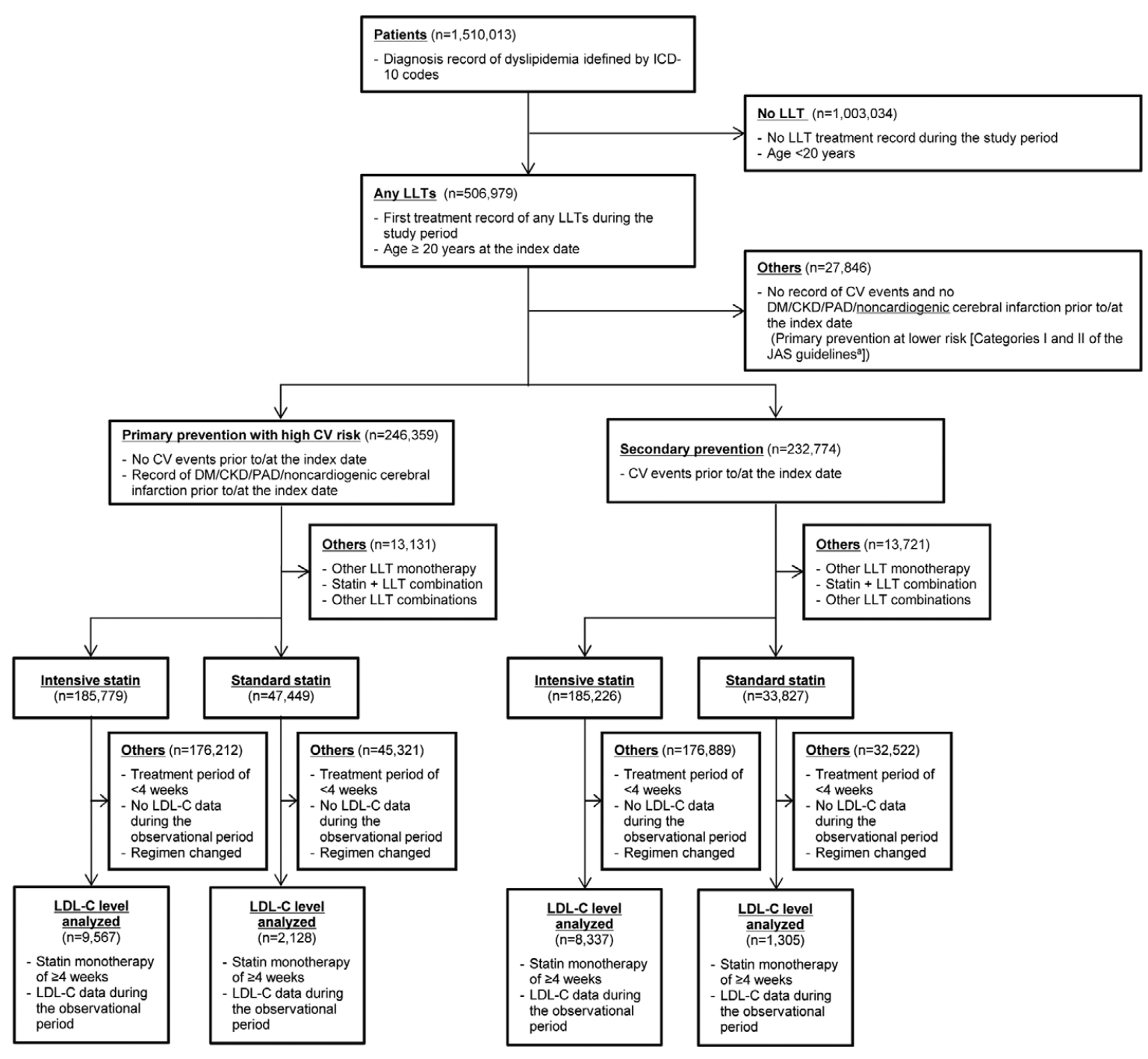

Figure 2. Patient disposition. aRisk group categories were classified in accordance with the Japan Atherosclerosis Society guidelines. ${ }^{14}$ CKD, chronic kidney disease; CV, cardiovascular; DM, diabetes mellitus; ICD-10, 10th Revision of the International Classification of Diseases; LDL-C, low-density lipoprotein cholesterol; LLT, lipid-lowering therapy; PAD, peripheral arterial disease.

secondary prevention group) and type of statin (intensive and standard), thus categorizing the patients into the following 4 groups: primary prevention with high $\mathrm{CV}$ risk receiving intensive statin therapy; primary prevention with high $\mathrm{CV}$ risk receiving standard statin therapy; secondary prevention receiving intensive statin therapy; and secondary prevention receiving standard statin therapy. Patient demographics and baseline characteristics were descriptively analyzed. Continuous variables are presented as means and standard deviations or medians and interquartile ranges, and categorical variables are presented as numbers and/or percentages. The LDL-C GA rates and 95\% confidence intervals (CIs) were estimated based on the target goals of $<120$ and $<100 \mathrm{mg} / \mathrm{dL}$ for the primary prevention with high $\mathrm{CV}$ risk and secondary prevention groups, respectively, ${ }^{14}$ using the Wilson score method. ${ }^{24}$ In the exploratory analyses, the achievement rates of more aggressive LDL-C thresholds were also estimated: $<100$ and $<70 \mathrm{mg} / \mathrm{dL}$ for the primary prevention with high CV risk group and secondary prevention group, respectively. In addition, the LDL-C GA rates and the GA rates of the more aggressive LDL-C thresholds were further estimated and stratified by disease complications. Statistical analyses were performed using SAS Release 9.4 (SAS Institute, Inc., Cary, NC, USA).

\section{Results}

\section{Patient Demography}

In total, 1,501,013 patients with a diagnostic record of dyslipidemia were identified. Of the 506,979 patients aged $\geq 20$ years and treated with any LLT, 246,359 (48.6\%) were classified into the primary prevention with high $\mathrm{CV}$ risk group and 232,774 (45.9\%) were classified into the secondary prevention group (Figure 2).

Among patients treated with LLT, most were on intensive statin therapy in both the primary and secondary prevention 
Primary prevention with high $\mathrm{CV}$ risk

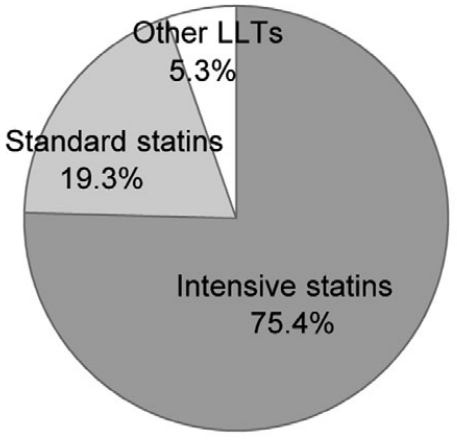

Secondary prevention

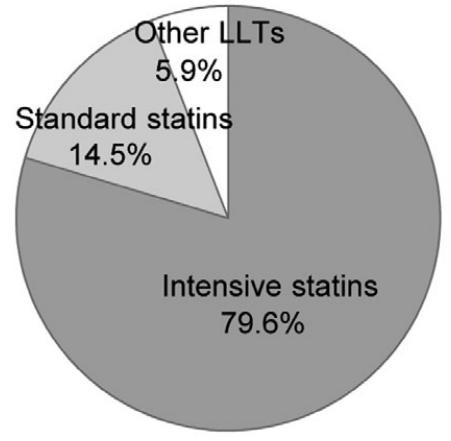

Figure 3. Treatment patterns of initial lipidlowering therapy (LLT) in patients with dyslipidemia. Both intensive statins and standard stains are monotherapy. Other LLT includes other LLT monotherapy, combination of statin and LLT(s), and combination of other LLTs. $\mathrm{CV}$, cardiovascular.

\begin{tabular}{|c|c|c|c|c|c|c|}
\hline \multirow[b]{2}{*}{ Characteristics } & \multicolumn{3}{|c|}{ Primary prevention with high CV risk } & \multicolumn{3}{|c|}{ Secondary prevention } \\
\hline & $\begin{array}{c}\text { Overall } \\
(n=11,695)\end{array}$ & $\begin{array}{l}\text { Intensive statins } \\
\quad(n=9,567)\end{array}$ & $\begin{array}{c}\text { Standard statins } \\
(n=2,128)\end{array}$ & $\begin{array}{l}\text { Overall } \\
(n=9,642)\end{array}$ & $\begin{array}{l}\text { Intensive statins } \\
\qquad(\mathrm{n}=\mathbf{8}, \mathbf{3 3 7})\end{array}$ & $\begin{array}{l}\text { Standard statins } \\
(n=1,305)\end{array}$ \\
\hline Age (years), mean $\pm S D$ & $65.5 \pm 12.4$ & $64.7 \pm 12.4$ & $68.8 \pm 11.8$ & $69.8 \pm 11.2$ & $69.1 \pm 11.3$ & $73.7 \pm 10.3$ \\
\hline Sex, male, n (\%) & $5,734(49.0)$ & $4,790(50.1)$ & $944(44.4)$ & $6,447(66.9)$ & $5,739(68.8)$ & $708(54.3)$ \\
\hline BMI $\left(\mathrm{kg} / \mathrm{m}^{2}\right), \mathrm{n}$ & 3,231 & 2,746 & 485 & 4,459 & 4,090 & 369 \\
\hline Mean \pm SD & $24.6 \pm 4.6$ & $24.7 \pm 4.6$ & $24.0 \pm 4.7$ & $24.2 \pm 4.2$ & $24.3 \pm 4.2$ & $23.5 \pm 3.9$ \\
\hline Smoking status, $\mathrm{n}$ & 3,093 & 2,628 & 465 & 4,190 & 3,847 & 343 \\
\hline Smoking, $n(\%)$ & $1,267(41.0)$ & $1,102(41.9)$ & $165(35.5)$ & $2,184(52.1)$ & $2,037(53.0)$ & $147(42.9)$ \\
\hline \multicolumn{7}{|l|}{ Smoking index } \\
\hline Mean \pm SD & $760.7 \pm 574.1$ & $756.9 \pm 568.8$ & $786.5 \pm 609.7$ & $823.5 \pm 694.4$ & $824.2 \pm 697.4$ & $814.1 \pm 652.9$ \\
\hline Median (25-75th IQR) & $\begin{array}{c}680 \\
(380.0-1,000.0)\end{array}$ & $\begin{array}{c}673.5 \\
(372.0-1,000.0)\end{array}$ & $\begin{array}{c}700 \\
(400.0-960.0)\end{array}$ & $\begin{array}{c}720 \\
(420.0-1,000.0)\end{array}$ & $\begin{array}{c}720 \\
(435.0-1,000.0)\end{array}$ & $\begin{array}{c}740 \\
(350.0-1,000.0)\end{array}$ \\
\hline eGFR (mL/min/1.73 m²), n & 8,322 & 6,885 & 1,437 & 7,047 & 6,205 & 842 \\
\hline Mean \pm SD & $67.3 \pm 25.4$ & $67.6 \pm 25.7$ & $66.2 \pm 23.7$ & $63.9 \pm 23.7$ & $64.3 \pm 23.8$ & $60.4 \pm 22.0$ \\
\hline \multicolumn{7}{|l|}{ History of CV event } \\
\hline Angina pectoris, $\mathrm{n}(\%)$ & - & - & - & 7,925 (82.2) & $6,761(81.1)$ & $1,164(89.2)$ \\
\hline MI, n (\%) & - & - & - & $4,202(43.6)$ & $3,801(45.6)$ & $401(30.7)$ \\
\hline \multicolumn{7}{|l|}{ Complications } \\
\hline $\mathrm{DM}, \mathrm{n}(\%)$ & $9,177(78.5)$ & $7,502(78.4)$ & $1,675(78.7)$ & $4,761(49.4)$ & $4,076(48.9)$ & $685(52.5)$ \\
\hline Hypertension, n (\%) & $8,082(69.1)$ & $6,557(68.5)$ & $1,525(71.7)$ & $8,032(83.3)$ & $6,913(82.9)$ & $1,119(85.7)$ \\
\hline CKD, n (\%) & $1,265(10.8)$ & $1,074(11.2)$ & $191(9.0)$ & $853(8.8)$ & $743(8.9)$ & $110(8.4)$ \\
\hline PAD, n (\%) & $1,194(10.2)$ & $975(10.2)$ & $219(10.3)$ & $1,942(20.1)$ & $1,660(19.9)$ & $282(21.6)$ \\
\hline $\begin{array}{l}\text { Noncardiogenic cerebral } \\
\text { infarction, } \mathrm{n}(\%)\end{array}$ & $3,069(26.2)$ & $2,510(26.2)$ & $559(26.3)$ & $1,788(18.5)$ & $1,472(17.7)$ & $316(24.2)$ \\
\hline
\end{tabular}

aTo obtain the smoking index, the number of cigarettes per day was multiplied by the number of years that a patient had smoked. An index of $>400$ was considered as heavy smoking. BMI, body mass index; CKD, chronic kidney disease; CV, cardiovascular; DM, diabetes mellitus; eGFR, estimated glomerular filtration rate; IQR, interquartile range; MI, myocardial infarction; PAD, peripheral arterial disease; SD, standard deviation.

groups $(\mathrm{n}=185,779[75.4 \%]$ and $\mathrm{n}=185,226[79.6 \%]$, respectively), while the proportions of patients on standard statin therapy were $15-19 \%$ in these prevention groups (Figures 2,3). Of the patients who met the further study eligibility criteria, 9,567 (81.8\%) were treated with intensive statins and 2,128 (18.2\%) with standard statins in the primary prevention with high CV risk group. Similarly, $8,337(86.5 \%)$ were treated with intensive statins and 1,305 $(13.5 \%)$ with standard statins in the secondary prevention group.

\section{Patients' Characteristics}

The patients' characteristics are summarized in Table 1. Overall, patients in the secondary prevention group were slightly older than their counterparts $(65.5 \pm 12.4$ vs. $69.8 \pm 11.2$ years), and patients treated with standard statins were approximately 4 years older than those treated with intensive statins in both prevention groups.

More than half $(67 \%)$ of the patients in the secondary prevention group were male, whereas the sex distribution in the primary prevention with high $\mathrm{CV}$ risk group was almost equal (male: $44-50 \%$ ). The mean body mass index was similar across all 4 groups $\left(24-25 \mathrm{~kg} / \mathrm{m}^{2}\right)$. 


\begin{tabular}{|c|c|c|c|c|c|}
\hline \multicolumn{6}{|c|}{ Primary prevention with high CV risk } \\
\hline \multirow{3}{*}{ Type of statin } & \multirow{3}{*}{$\begin{array}{l}\text { Patients on } \\
\text { statin, } n,(\%)\end{array}$} & \multicolumn{2}{|c|}{ LDL-C goal of $<120 \mathrm{mg} / \mathrm{dL}$} & \multicolumn{2}{|c|}{ LDL-C goal of $<100 \mathrm{mg} / \mathrm{dL}$} \\
\hline & & \multirow{2}{*}{$\begin{array}{l}\text { Patients reaching } \\
\text { LDL-C goal, } n\end{array}$} & GA rate & \multirow{2}{*}{$\begin{array}{l}\text { Patients reaching } \\
\text { LDL-C goal, } n\end{array}$} & GA rate \\
\hline & & & $\%(95 \% \mathrm{Cl})$ & & $\%(95 \% \mathrm{Cl})$ \\
\hline Overall & $11,695(100)$ & 9,065 & $77.5(76.7-78.3)$ & 6,156 & $52.6(51.7-53.5)$ \\
\hline Intensive statins & $9,567(81.8)$ & 7,762 & $81.1(80.3-81.9)$ & 5,517 & $57.7(56.7-58.7)$ \\
\hline Standard statins & $2,128(18.2)$ & 1,303 & $61.2(59.1-63.3)$ & 639 & $30.0(28.2-32.0)$ \\
\hline \multicolumn{6}{|l|}{ Secondary prevention } \\
\hline \multirow{3}{*}{ Type of statin } & \multirow{3}{*}{$\begin{array}{l}\text { Patients on } \\
\text { statin, } n,(\%)\end{array}$} & \multicolumn{2}{|c|}{ LDL-C goal of $<100 \mathrm{mg} / \mathrm{dL}$} & \multicolumn{2}{|c|}{ LDL-C goal of $<70 \mathrm{mg} / \mathrm{dL}$} \\
\hline & & \multirow{2}{*}{$\begin{array}{l}\text { Patients reaching } \\
\text { LDL-C goal, } n\end{array}$} & GA rate & \multirow{2}{*}{$\begin{array}{l}\text { Patients reaching } \\
\text { LDL-C goal, } n\end{array}$} & GA rate \\
\hline & & & $\%(95 \% \mathrm{Cl})$ & & $\%(95 \% \mathrm{Cl})$ \\
\hline Overall & $9,642(100)$ & 6,738 & $69.9(69.0-70.8)$ & 2,180 & $22.6(21.8-23.5)$ \\
\hline Intensive statins & $8,337(86.5)$ & 6,110 & $73.3(72.3-74.2)$ & 2,054 & $24.6(23.7-25.6)$ \\
\hline Standard statins & $1,305(13.5)$ & 628 & $48.1(45.4-50.8)$ & 126 & $9.7(8.2-11.4)$ \\
\hline
\end{tabular}

$\mathrm{Cl}$, confidence interval; CV, cardiovascular; GA, goal attainment; LDL-C, low-density lipoprotein cholesterol.
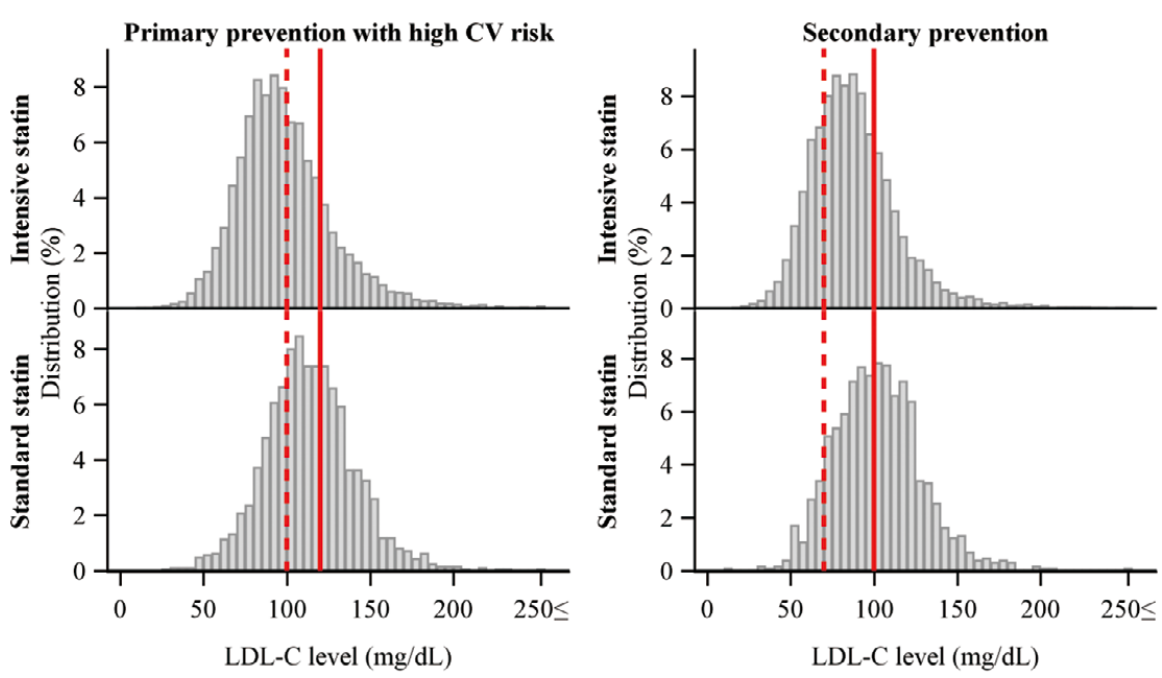

Figure 4. Distributions of low-density lipoprotein cholesterol (LDL-C) and rates of achieving LDL-C target levels. The red solid line designates the target LDL-C level recommended by the Japan Atherosclerosis Society guidelines for each prevention group: $120 \mathrm{mg} / \mathrm{dL}$ (primary prevention with high CV risk group) and $100 \mathrm{mg} / \mathrm{dL}$ (secondary prevention group). ${ }^{14}$ The red dotted line designates the LDL-C level of $100 \mathrm{mg} / \mathrm{dL}$ (primary prevention with high $\mathrm{CV}$ risk group) and $70 \mathrm{mg} / \mathrm{dL}$ (secondary prevention group). CV, cardiovascular.

Most patients in the secondary prevention group had a history of angina pectoris $(81.1 \%$ on intensive statins, $89.2 \%$ on standard statins). The prevalence of disease complications (DM, hypertension, CKD, PAD, and noncardiogenic cerebral infarction) was comparable between the types of statins within each prevention group. DM and hypertension were predominant in the primary and secondary prevention groups $(\approx 80 \%$ and $50 \%$ in the primary prevention group and $\approx 70 \%$ and $80 \%$ in the secondary prevention group, respectively).

\section{Achievement of LDL-C Targets}

The overall rates of achieving the LDL-C goals set by the guidelines were relatively higher in the primary than in the secondary prevention group. In the primary prevention group, the GA rates for the LDL-C target $<120 \mathrm{mg} / \mathrm{dL}$ were $81.1 \%(95 \% \mathrm{CI}: 80.3-81.9)$ and $61.2 \%(59.1-63.3)$ in patients treated with intensive and standard statins, respectively (Table 2). In the secondary prevention group, the GA rates for the LDL-C target $<100 \mathrm{mg} / \mathrm{dL}$ were $73.3 \%$ $(72.3-74.2)$ and $48.1 \%(45.4-50.8)$ in patients treated with intensive and standard statins, respectively.

Using the more aggressive LDL-C goals, the GA rates for an LDL-C level $<100 \mathrm{mg} / \mathrm{dL}$ in the primary prevention group were $57.7 \%(56.7-58.7)$ and $30.0 \%(28.1-32.0)$ in patients treated with intensive and standard statins, respectively, and the corresponding GA rates for an LDL-C level $<70 \mathrm{mg} / \mathrm{dL}$ in the secondary prevention group were $24.6 \%$ (23.7-25.6) and 9.7\% (8.2-11.4) in patients treated with intensive and standard statins, respectively. 
Table 3. LDL-C GA Rates According to Complications by Prevention Group and Type of Statin

Primary prevention with high CV risk

\begin{tabular}{|c|c|c|c|c|}
\hline & \multirow{3}{*}{$\begin{array}{l}\text { Patients } \\
\text { prescribed } \\
\text { statins, } n\end{array}$} & \multicolumn{3}{|c|}{ Intensive statins } \\
\hline & & \multirow{2}{*}{$\begin{array}{c}\text { Patients } \\
\text { prescribed } \\
\text { intensive } \\
\text { statins, n (\%) }\end{array}$} & \multicolumn{2}{|c|}{ LDL-C goal of $<120 \mathrm{mg} / \mathrm{dL}$} \\
\hline & & & $\begin{array}{l}\text { Patients reaching } \\
\text { LDL-C goal, } n\end{array}$ & $\begin{array}{l}\text { GA rate, } \%, \\
(95 \% \mathrm{Cl})\end{array}$ \\
\hline \multicolumn{5}{|l|}{ Complications ${ }^{a}$} \\
\hline DM & 9,177 & $7,502(81.7)$ & 6,053 & $80.7(79.8-81.6)$ \\
\hline PAD & 1,194 & $975(81.7)$ & 816 & $83.7(81.2-85.9)$ \\
\hline CKD & 1,265 & $1,074(84.9)$ & 890 & $82.9(80.5-85.0)$ \\
\hline Noncardiogenic cerebral infarction & 3,069 & $2,510(81.8)$ & 2,145 & $85.5(84.0-86.8)$ \\
\hline \multicolumn{5}{|l|}{ Secondary prevention } \\
\hline & & \multicolumn{3}{|c|}{ Intensive statins } \\
\hline & \multirow{2}{*}{$\begin{array}{l}\text { Patients } \\
\text { prescribed } \\
\text { statins, } n\end{array}$} & & \multicolumn{2}{|c|}{ LDL-C goal of $<100 \mathrm{mg} / \mathrm{dL}$} \\
\hline & & $\begin{array}{c}\text { intensive } \\
\text { statins, } n(\%)\end{array}$ & $\begin{array}{l}\text { Patients reaching } \\
\text { LDL-C goal, } n\end{array}$ & $\begin{array}{l}\text { GA rates, \%, } \\
(95 \% \mathrm{Cl})\end{array}$ \\
\hline \multicolumn{5}{|l|}{ Complications $^{a}$} \\
\hline Angina pectoris & 7,925 & $6,761(85.3)$ & 4,930 & $72.9(71.8-74.0)$ \\
\hline MI & 4,202 & $3,801(90.5)$ & 2,888 & $76.0(74.6-77.3)$ \\
\hline DM & 4,761 & $4,076(85.6)$ & 3,063 & $75.1(73.8-76.4)$ \\
\hline PAD & 1,942 & $1,660(85.5)$ & 1,241 & $74.8(72.6-76.8)$ \\
\hline CKD & 853 & $743(87.1)$ & 592 & $79.7(76.6-82.4)$ \\
\hline Noncardiogenic cerebral infarction & 1,788 & $1,472(82.3)$ & 1,099 & $74.7(72.4-76.8)$ \\
\hline
\end{tabular}

aThe sum of percentages sometimes exceeded 100\% because some patients had multiple complications. Cl, confidence interval; CKD, chronic kidney disease; CV, cardiovascular; DM, diabetes mellitus; GA, goal attainment; LDL-C, low-density lipoprotein cholesterol; MI, myocardial infarction; PAD, peripheral arterial disease.

(Table 3 continued the next page.)

\section{Distributions of LDL-C Levels}

The LDL-C levels were symmetrically distributed across the 4 groups (Figure 4). The mean LDL-C levels met the goals defined by the guidelines for the patients in all groups except those prescribed standard statin therapy in the secondary prevention group $(101.7 \pm 26.1 \mathrm{mg} / \mathrm{dL})$.

Of the patients who achieved the target, $47.0-77.9 \%$ in the 4 groups had LDL-C levels just below their target goals $(-30 \mathrm{mg} / \mathrm{dL})$ (data not shown). Of the patients who failed to achieve the treatment goals, the majority $(72-78 \%)$ was clustered just above the treatment target $(+30 \mathrm{mg} / \mathrm{dL})$ among the 4 groups.

\section{Achievement of LDL-C Goal by Disease Complications}

Overall, no specific trend in the GA rates based on disease complications was observed. Among patients prescribed intensive statin therapy in the primary prevention with high $\mathrm{CV}$ risk group, the GA rate for the target of $<120 \mathrm{mg} / \mathrm{dL}$ ranged from $80.7 \%$ to $85.5 \%$ and did not vary regardless of the background diseases (Table 3), despite the fact that $78.4 \%$ had DM and 26.2\% had noncardiogenic cerebral infarction (Table 1). Similarly, among patients treated with intensive statins in the secondary prevention group, $81.1 \%$ and $45.6 \%$ had angina pectoris and MI, respectively (Table 1), yet the GA rates for the target of $<100 \mathrm{mg} / \mathrm{dL}$ ranged from $72.9 \%$ to $79.7 \%$ (Table 3 ).

\section{Discussion}

In this study, we estimated the rates of achieving LDL-C management goals by initial statin monotherapy in patients with dyslipidemia in Japan using a large-scale healthcare claims database. Overall, the rates of achieving the LDL-C goal were generally higher than in previous studies, which suggested that the implementation of active treatment by initial statins leads to appropriate LDL-C management in the majority of patients $(\approx 70 \%)$.

Compared with previous studies, the present study found higher rates of achieving LDL-C levels for optimal management: $77.5 \%$ in primary prevention and $69.9 \%$ in secondary prevention. In a 2013 study, the LDL-C GA rate for a goal of $<130 \mathrm{mg} / \mathrm{dL}$ was $80 \%$ in patients with ischemic stroke, PAD, and DM and that for a goal of $<100 \mathrm{mg} / \mathrm{dL}$ was $55 \%$ and $68 \%$ in patients with other CAD and recent acute coronary syndrome, respectively. ${ }^{23}$ Similarly, in the $2010 \mathrm{JL}-\mathrm{GAP}$ study, the LDL-C GA rate of the JAS target goals by statin monotherapy was $56.5 \%$ in the primary prevention with high $\mathrm{CV}$ risk group and $24.5 \%$ in the secondary prevention group. ${ }^{16}$ These gaps could be explained by differences in the target patients, treatments, statin intensity, and healthcare institutions where the data were obtained. The present study targeted dyslipidemic patients in primary prevention with high $\mathrm{CV}$ risk and secondary prevention groups treated at acute care hospitals and whose statin monotherapy was predominantly intensive $(82-87 \%)$. On the other hand, the previous studies did not limit their target to dyslipidemic patients, included only approximately $45-67 \%$ of patients treated with statin or other LLT, and/or included patients treated at university hospitals, general hospitals, and primary care clinics. Together with these differences among the previous studies, the improvement in GA rates in our study suggested that 
Intensive statins

\begin{tabular}{|c|c|}
\hline \multicolumn{2}{|c|}{ LDL-C goal of $<100 \mathrm{mg} / \mathrm{dL}$} \\
\hline $\begin{array}{c}\text { Patients reaching } \\
\text { LDL-C goal, } \mathbf{n}\end{array}$ & $\begin{array}{c}\text { GA rate, \%, } \\
(95 \% \mathrm{Cl})\end{array}$ \\
\hline
\end{tabular}

\begin{tabular}{ccc}
\hline Patients & \multicolumn{2}{c}{ LDL-C goal of $<120 \mathrm{mg} / \mathrm{dL}$} \\
\cline { 2 - 3 } prescribed & Patients reaching & GA rate, $\%$, \\
standard & LDL-C goal, $\mathrm{n}$ & $(95 \% \mathrm{Cl})$
\end{tabular}

$\begin{array}{rr}1,675(18.3) & 1,017 \\ 219(18.3) & 147 \\ 191(15.1) & 132 \\ 559(18.2) & 371\end{array}$

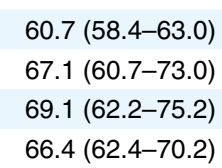

LDL-C
Patients rea
LDL-C goa

471
81
85
198

Standard statins

\begin{tabular}{ccccccc}
\hline Patients & \multicolumn{2}{c}{ LDL-C goal of $<100 \mathrm{mg} / \mathrm{dL}$} & & \multicolumn{2}{c}{ LDL-C goal of $<70 \mathrm{mg} / \mathrm{dL}$} \\
\cline { 2 - 3 } \cline { 5 - 6 } $\begin{array}{c}\text { prescribed } \\
\text { standard } \\
\text { statins, } \mathrm{n}(\%)\end{array}$ & $\begin{array}{c}\text { Patients reaching } \\
\text { LDL-C goal, } \mathrm{n}\end{array}$ & $\begin{array}{c}\text { GA rates, \%, } \\
(95 \% \mathrm{Cl})\end{array}$ & & $\begin{array}{c}\text { Patients reaching } \\
\text { LDL-C goal, } \mathrm{n}\end{array}$ & $\begin{array}{c}\text { GA rate, } \%, \\
(95 \% \mathrm{Cl})\end{array}$
\end{tabular}

\begin{tabular}{c}
$\frac{\text { Intensive statins }}{\text { LDL-C goal of }<70 \mathrm{mg} / \mathrm{dL}}$ \\
\hline $\begin{array}{c}\text { Patients reaching } \\
\text { LDL-C goal, } \mathrm{n}\end{array}$ \\
$\begin{array}{r}\text { GA rate, } \%, \\
(95 \% \mathrm{Cl})\end{array}$
\end{tabular}

$\begin{array}{rr}1,653 & 24.4(23.4-25.5) \\ 982 & 25.8(24.5-27.3) \\ 1,139 & 27.9(26.6-29.3) \\ 452 & 27.2(25.1-29.4) \\ 271 & 36.5(33.1-40.0) \\ 399 & 27.1(24.9-29.4)\end{array}$

$\begin{array}{cr}1,164(14.7) & 557 \\ 401(9.5) & 220 \\ 685(14.4) & 348 \\ 282(14.5) & 147 \\ 110(12.9) & 64 \\ 316(17.7) & 158\end{array}$

$47.9(45.0-50.7)$
$54.9(50.0-59.7)$
$50.8(47.1-54.5)$
$52.1(46.3-57.9)$
$58.2(48.8-67.0)$
$50.0(44.5-55.5)$

$10.1(8.5-11.9)$

$11.5(8.7-15.0)$ $10.7(8.6-13.2)$

$11.3(8.2-15.6)$

$21.8(15.1-30.4)$

$10.8(7.8-14.7)$ the LDL-C goals in the guidelines are becoming more widely recognized by physicians and that increased efforts have been made to comply with these goals from 2010 to date.

Although the majority of patients $(\approx 70-80 \%)$ in both groups achieved the LDL-C goals in the present study, the remaining patients who did not achieve the JAS guideline goals by initial statin monotherapy required further control of their LDL-C level. This is crucial for patients on secondary prevention with a greater risk for recurrent $\mathrm{CV}$ events. ${ }^{25}$ Based on the LDL-C goal of $<70 \mathrm{mg} / \mathrm{dL}$ for secondary prevention specified in the European Society of Cardiology guidelines, ${ }^{26}<25 \%$ of patients in this study achieved the goal even under treatment with intensive statins. The JAS guidelines were recently updated in 2017; in the update, the more aggressive treatment goal of $<70 \mathrm{mg} / \mathrm{dL}$ was established for secondary prevention, especially if accompanied by familial hyperdyslipidemia, acute coronary syndrome, or DM with other high-risk factors such as noncardiogenic cerebral infarction, PAD, or CKD. ${ }^{27}$ We additionally assessed GA rates in accordance with the updated guidelines, ${ }^{27}$ targeting those patients. The GA rates for the LDL-C goal of $<70 \mathrm{mg} / \mathrm{dL}$ were $27.3 \%(25.9-28.8)$ and $11.3 \%(8.6-14.5)$ in patients treated with intensive and standard statins, respectively (Table S1), which were similar to the GA rates in patients with secondary prevention. The GA rates were similar among patients with different disease complications, except for those with familial hyperdyslipidemia. For these patients not fully controlled by statin monotherapy, physicians should choose the most appropriate treatment to achieve the LDL-C goal, such as doubling the dosage of initial statins, ${ }^{28}$ and/or adding other LLT such as ezetimibe to the initial statin, ${ }^{29}$ which could be expected to result in a decreased LDL-C.

The ultimate goal of controlling LDL-C is lifetime prevention of CV events. In our study, patients with good adherence $(\geq 80 \%)$ to intensive or standard statin monotherapy constituted $88.4 \%$ and $89.5 \%$ of those in the primary prevention with high CV risk group and $84.0 \%$ and $89.0 \%$ of those in the secondary prevention group, respectively (the adherence rate was estimated by the proportion of days covered based on the prescription history of initial statin monotherapy from the index date to first LDL-C measurement from $>4$ to $\leq 52$ weeks) (Table S2). This high adherence rate could have contributed to the relatively high GA rates observed in this study. For those who achieve the LDL-C goal, maintaining an optimal LDL-C level for the long term is another challenge in CVD prevention because of the asymptomatic nature of dyslipidemia, ${ }^{30}$ and its prolonged treatment period, resulting in low adherence to treatment ${ }^{31-34}$ and thus an increased risk of CV events. ${ }^{35}$

In real-world clinical settings, it is crucial to identify the patients at high CV risk in the primary prevention group. The Japan Lipid Intervention Trial (J-LIT) study showed that LDL-C concentration ranges between 100-119 and $120-139 \mathrm{mg} / \mathrm{dL}$ were not significantly different for coronary risk in the patients with primary prevention. ${ }^{36} \mathrm{~A}$ subanalysis of the same population in the J-LIT study showed that the risk of coronary events increased in those with type $2 \mathrm{DM}$ (T2DM) as complications compared with those without T2DM. ${ }^{37}$ It is necessary to comprehensively manage LDL-C levels taking into consideration the $\mathrm{CV}$ risks and the cost-effectiveness in individual patients.

\section{Study Limitations}

A retrospective cohort study using the herein-described hospital-based claims MDV database was considered to be the most appropriate approach for investigating patients with dyslipidemia and high $\mathrm{CV}$ risk in the real-world setting; 
however, the study design has inherent limitations. First, the generalizability of the results to patients with dyslipidemia in Japan may be somewhat limited because the data were obtained from acute care hospitals. Thus, further investigation of clinics and non-acute care hospitals is required. Second, the first statin prescription was identified in the hospital participating in this database during this study period, which may have resulted in the inclusion of patients who were prescribed statins before enrollment in this study. Third, this study was performed to evaluate the effectiveness of initial treatment with statins; the effects of neither further dose adjustments (i.e., intensifications) nor switching to other statins were evaluated. Thus, our results may not reflect the effects of statin treatment at any dosage.

\section{Conclusions}

Using a large hospital-based claims database, the present study estimated the LDL-C GA rates in patients with dyslipidemia treated with statin monotherapy. In total, $77.5 \%$ and $69.9 \%$ of patients in the primary prevention with high $\mathrm{CV}$ risk group and secondary prevention group, respectively, achieved the LDL-C goals defined in the JAS guidelines in 2012. Patients who do not achieve the LDL-C goals by initial statin monotherapy require more aggressive treatment approaches towards achievement of the LDL-C targets. Further efforts are required to ensure persistent and adherent LLT, which could be the key to success for continuous and life-long management of LDL-C for the purpose of decreasing potential $\mathrm{CV}$ risks.

\section{Acknowledgments}

The authors thank Aya Murakami and Mika Kawaguchi for their substantial contributions to the study, and Clinical Study Support, Inc. for statistical, writing, and editorial assistance, provided under contract with MSD K.K., Tokyo, Japan. This study was funded by MSD K.K. The sponsor was involved in the study design, data analysis, interpretation of the data, writing of the manuscript, and decision to submit the manuscript for publication.

\section{Disclosure}

T.U., C.A.B., and S.T. had stock/stock options of Merck. T.T. received remuneration from Bayer Yakuhin, Pfizer Japan, Daiichi Sankyo, Kowa, Takeda Pharmaceutical, Astellas Pharma, Kissei Pharmaceutical, Sanofi, Amgen Astellas BioPharma, and MSD. T.T. received research funding from Daiichi Sankyo, Kowa, Eli Lilly Japan, Takeda Pharmaceutical, and Shionogi. T.T. was affiliated with an endowed department sponsored by Bayer Yakuhin, Kowa, Astellas Pharma, Kissei Pharmaceutical, MSD, Mochida Pharmaceutical, Aska Pharmaceutical, and MSD. A. Hayashi, A. Harada, and K.O. have no conflicts of interest to disclose.

\section{References}

1. World Health Organization. Cardiovascular diseases (CVDs) Fact sheet (in Japanese). http://www.who.int/mediacentre/factsheets/ fs317/en/ (accessed September 13, 2016).

2. Ministry of Health, Labour and Welfare. Summary report of vital statistics of Japan (final data) in 2015 (in Japanese). http:// www.mhlw.go.jp/toukei/saikin/hw/jinkou/kakutei15/index.html (accessed September 13, 2016).

3. Imano H, Noda H, Kitamura A, Sato S, Kiyama M, Sankai T, et al. Low-density lipoprotein cholesterol and risk of coronary heart disease among Japanese men and women: The Circulatory Risk in Communities Study (CIRCS). Prev Med 2011; 52: 381386.

4. Shepherd J, Cobbe SM, Ford I, Isles CG, Lorimer AR, MacFarlane PW, et al. Prevention of coronary heart disease with pravastatin in men with hypercholesterolemia: West of Scotland Coronary Prevention Study Group. N Engl J Med 1995; 333:
1301-1307.

5. Downs JR, Clearfield M, Weis S, Whitney E, Shapiro DR, Beere PA, et al. Primary prevention of acute coronary events with lovastatin in men and women with average cholesterol levels: Results of AFCAPS/TexCAPS [Air Force/Texas Coronary Atherosclerosis Prevention Study]. JAMA 1998; 279: 1615-1622.

6. Scandinavian Simvastatin Survival Study Group. Randomised trial of cholesterol lowering in 4444 patients with coronary heart disease: The Scandinavian Simvastatin Survival Study (4S). Lancet 1994; 344: 1383-1389.

7. Heart Protection Study Collaborative Group. MRC/BHF Heart Protection Study of cholesterol lowering with simvastatin in 20,536 high-risk individuals: A randomised placebo-controlled trial. Lancet 2002; 360: 7-22.

8. Cholesterol Treatment Trialists' (CTT) Collaboration, Baigent C, Blackwell L, Emberson J, Holland LE, Reith C, Bhala N, et al. Efficacy and safety of more intensive lowering of LDL cholesterol: A meta-analysis of data from 170,000 participants in 26 randomised trials. Lancet 2010; 376: 1670-1681.

9. Nakamura H, Arakawa K, Itakura H, Kitabatake A, Goto Y, Toyota T, et al; MEGA Study Group. Primary prevention of cardiovascular disease with pravastatin in Japan (MEGA Study): A prospective randomised controlled trial. Lancet 2006; 368: $1155-1163$.

10. Cannon CP, Braunwald E, McCabe CH, Rader DJ, Rouleau JL, Belder R, et al; Pravastatin or Atorvastatin Evaluation and Infection Therapy-Thrombolysis in Myocardial Infarction 22 Investigators. Intensive versus moderate lipid lowering with statins after acute coronary syndromes. N Engl J Med 2004; 350: $1495-1504$.

11. Pedersen TR, Faergeman O, Kastelein JJ, Olsson AG, Tikkanen MJ, Holme I, et al; Incremental Decrease in End Points Through Aggressive Lipid Lowering (IDEAL) Study Group. High-dose atorvastatin vs. usual-dose simvastatin for secondary prevention after myocardial infarction: The IDEAL study: A randomized controlled trial. JAMA 2005; 294: 2437-2445.

12. Stone NJ, Robinson JG, Lichtenstein AH, Bairey Merz CN, Blum CB, Eckel RH, et al; American College of Cardiology/ American Heart Association Task Force on Practice Guidelines. 2013 ACC/AHA guideline on the treatment of blood cholesterol to reduce atherosclerotic cardiovascular risk in adults: A report of the American College of Cardiology/American Heart Association Task Force on Practice Guidelines. J Am Coll Cardiol 2014; 63: 2889-2934.

13. Task Force Members: Piepoli MF, Hoes AW, Agewall S, Albus C, Brotons C, Catapano AL, et al. 2016 European Guidelines on cardiovascular disease prevention in clinical practice: The Sixth Joint Task Force of the European Society of Cardiology and Other Societies on Cardiovascular Disease Prevention in Clinical Practice (constituted by representatives of 10 societies and by invited experts). Developed with the special contribution of the European Association for Cardiovascular Prevention \& Rehabilitation (EACPR). Eur Heart J 2016; 37: 2315-2381.

14. Teramoto T, Sasaki J, Ishibashi S, Birou S, Daida H, Dohi S, et al; Japan Atherosclerosis Society. Executive summary of the Japan Atherosclerosis Society (JAS) guidelines for the diagnosis and prevention of atherosclerotic cardiovascular diseases in Japan-2012 version. J Atheroscler Thromb 2013; 20: 517-523.

15. Teramoto $\mathrm{T}$, Kashiwagi A, Mabuchi H; J-Lap Investigators. Status of lipid-lowering therapy prescribed based on recommendations in the 2002 report of the Japan Atherosclerosis Society Guideline for Diagnosis and Treatment of Hyperlipidemia in Japanese Adults: A study of the Japan Lipid Assessment Program (J-LAP). Curr Ther Res Clin Exp 2005; 66: 80-95.

16. Teramoto T, Kashiwagi A, Ishibashi S, Daida H; Japan Lipid Guideline Achievement Program Investigators. Cross-sectional survey to assess the status of lipid management in high-risk patients with dyslipidemia: Clinical impact of combination therapy with ezetimibe. Curr Ther Res Clin Exp 2012; 73: 1-15.

17. Ministry of Health, Labour, and Welfare. Tabulation and estimation methods of the Patient's Survey 2014 (in Japanese). http://www.mhlw.go.jp/toukei/saikin/hw/kanja/14/d1/kanja.pdf (accessed May 30, 2017).

18. Yamana H, Moriwaki M, Horiguchi H, Kodan M, Fushimi K, Yasunaga $\mathrm{H}$. Validity of diagnoses, procedures, and laboratory data in Japanese administrative data. J Epidemiol 2017; 27: 476-482.

19. Pharmaceuticals and Medical Devices Agency. Interview Form (Lipitor) (in Japanese). http://www.info.pmda.go.jp/go/interview /1/800126_2189015F1023_1_1F (accessed May 30, 2017). 
20. Pharmaceuticals and Medical Devices Agency. Interview Form (Crestor) (in Japanese). http://www.info.pmda.go.jp/go/interview/ 1/670227_2189017F1022_1_181_1F (accessed May 30, 2017).

21. Pharmaceuticals and Medical Devices Agency. Interview Form (Zocor) (in Japanese). http://www.info.pmda.go.jp/go/interview /2/170050_2189011F1025_2_025_1F (accessed May 30, 2017).

22. Kondo Y, Hamai J, Nezu U, Shigematsu E, Kamiko K, Yamazaki S, et al. Second-line treatments for dyslipidemia in patients at risk of cardiovascular disease. Endocr J 2014; 61: $343-351$.

23. Teramoto T, Uno K, Miyoshi I, Khan I, Gorcyca K, Sanchez RJ, et al. Low-density lipoprotein cholesterol levels and lipidmodifying therapy prescription patterns in the real world: An analysis of more than 33,000 high cardiovascular risk patients in Japan. Atherosclerosis 2016; 251: 248-254.

24. Wilson EB. Probable inference, the law of succession, and statistical inference. J Am Stat Assoc 1927; 22: 209-212.

25. Mabuchi H, Kita T, Matsuzaki M, Matsuzawa Y, Nakaya N, Oikawa S, et al; J-LIT Study Group. Japan Lipid Intervention Trial. Large scale cohort study of the relationship between serum cholesterol concentration and coronary events with low-dose simvastatin therapy in Japanese patients with hypercholesterolemia and coronary heart disease: Secondary prevention cohort study of the Japan Lipid Intervention Trial (J-LIT). Circ J 2002; 66: $1096-1100$

26. Reiner Ž, Catapano AL, De Backer G, Graham I, Taskinen MR, Wiklund $\mathrm{O}$, et al. ESC/EAS Guidelines for the management of dyslipidaemias: The Task Force for the management of dyslipidaemias of the European Society of Cardiology (ESC) and the European Atherosclerosis Society (EAS). Eur Heart J 2011; 32: $1769-1818$.

27. Japan Atherosclerosis Society. Japan Atherosclerosis Society (JAS) guidelines for prevention of atherosclerotic cardiovascular diseases 2017 version. Tokyo: Japan Atherosclerosis Society, 2017.

28. McKenney JM. Optimizing LDL-C lowering with statins. Am J Ther 2004; 11: 54-59.

29. Teramoto T, Sawada T, Iwamoto K, Daida H. Clinical efficacy and tolerability of ezetimibe in combination with atorvastatin in Japanese patients with hypercholesterolemia: Ezetimibe phase IV randomized controlled trial in patients with hypercholesterolemia. Curr Ther Res Clin Exp 2012; 73: 16-40.

30. Tanaka T, Okamura T, Yamagata Z, Takebayashi T, Tamura U, Kusaka Y, et al; HIPOP-OHP Research Group. Awareness and treatment of hypertension and hypercholesterolemia in Japanese workers: The High-risk and Population Strategy for
Occupational Health Promotion (HIPOP-OHP) study. Hypertens Res 2007; 30: 921-928.

31. Haynes RB, McKibbon KA, Kanani R. Systematic review of randomised trials of interventions to assist patients to follow prescriptions for medications. Lancet 1996; 348: 383-386.

32. World Health Organization. Adherence to long-term therapies: Evidence for action. http://apps.who.int/iris/bitstream/10665/ 42682/1/9241545992.pdf (accessed July 1, 2017).

33. Chowdhury R, Khan H, Heydon E, Shroufi A, Fahimi S, Moore $\mathrm{C}$, et al. Adherence to cardiovascular therapy: A meta-analysis of prevalence and clinical consequences. Eur Heart J 2013; 34: $2940-2948$

34. Benner JS, Glynn RJ, Mogun H, Neumann PJ, Weinstein MC, Avorn J. Long-term persistence in use of statin therapy in elderly patients. JAMA 2002; 288: 455-461.

35. Tuppin P, Neumann A, Danchin N, de Peretti C, Weill A, Ricordeau $\mathrm{P}$, et al. Evidence-based pharmacotherapy after myocardial infarction in France: Adherence-associated factors and relationship with 30-month mortality and rehospitalization. Arch Cardiovasc Dis 2010; 103: 363-375.

36. Matsuzaki M, Kita T, Mabuchi H, Matsuzawa Y, Nakaya N, Oikawa S, et al; J-LIT Study Group. Japan Lipid Intervention Trial. Large scale cohort study of the relationship between serum cholesterol concentration and coronary events with low-dose simvastatin therapy in Japanese patients with hypercholesterolemia. Circ J 2002; 66: 1087-1095.

37. Oikawa S, Kita T, Mabuchi H, Matsuzaki M, Matsuzawa Y, Nakaya N, et al; J-LIT Study Group. Risk of coronary events in Japanese patients with both hypercholesterolemia and type 2 diabetes mellitus on low-dose simvastatin therapy: Implication from Japan Lipid Intervention Trial (J-LIT). Atherosclerosis 2007; 191: 440-446.

\section{Supplementary Files}

\section{Supplementary File 1}

Table S1. LDL-C GA rates according to the JAS guidelines 2017 (LDL-C goal of $<70 \mathrm{mg} / \mathrm{dL}$ ) in the secondary prevention group by type of statin

Table S2. Number of patients on statins stratified by CV prevention group according to adherence rate

Please find supplementary file(s);

http://dx.doi.org/10.1253/circj.CJ-17-0971 